\title{
ON TRACK
}

\section{How to Use the Annals Online Discussion}

Kurt C. Stange, $M D, P b D$, Editor

Ann Fam Med 2004;2:611-612. DOI: 10.1370/afm.249.

A s editor, one of my joys is reading the online discussion among diverse Annals readers and authors. I believe that this interactive forum is helping to create an intellectual center among those who practice, study, teach, administer, interact with, and receive primary care. The amount and thoughtfulness of the interaction is exceptional among peerreviewed, indexed research journals. Below I answer several questions about this online discussion.

\section{WHAT IS TRACK AND ON TRACK?}

The Annals online discussion groups are called TRACK (Topical Response to the Annals Community of Knowledge). TRACK is an opportunity for immediate and delayed commentary and interaction among readers and authors. ${ }^{1}$ Each published article has its own discussion group. The discussion also is accessible as a whole

In a feature called On $\mathrm{TRACK}^{2}{ }^{2}$ the editors attempt to synthesize the TRACK discussion since the last issue. These syntheses have ranged from brief summaries of the recent online discussion to more in-depth thematic analyses. On TRACK continues to evolve, and the editors welcome your thoughts as to what would be most useful.

\section{HOW CAN I JOIN THE CONVERSATION? HOW CAN I JUST "LISTEN IN"?}

When you read an article that interests you, I recommend going to the discussion periodically to see what additional perspectives the article has generated. Questions (often subsequently answered by the authors), interpretations, and exhortations ${ }^{3}$ can help bring the research to life by showing how the article's new knowledge interacts with the perspectives of diverse readers. Some exchanges, such as those generated in response to articles on the future of family medicine project, ${ }^{4,5}$ a study of childhood cancer survivors' health care ${ }^{6}$ or a study of patient preferences for spiritual discussions with their physician, ${ }^{7}$ generated a remarkable number and diversity of responses. A large number of responses are not needed to make reading worthwhile, however. For example, recent author responses and reader comments about articles on a new model of selfawareness for preventing errors in clinical practice, ${ }^{8} \mathrm{a}$ cascade analysis of medical errors, ${ }^{9}$ the documentation of a new cardiovascular risk factor, ${ }^{10}$ or patients' valuation of continuity of care ${ }^{11}$ show that a single thoughtful idea can be important.

I also recommend doing an occasional immersion in the discussion. On the Web site when you click on "Discussion of articles" you can specify the number of days of discussion you wish to view. Every now and then, try browsing through the thoughts of people within and outside the field as they come together around new research knowledge and personal experience. Like I do, you might find it inspiring.

\section{WHAT ARE THE BENEFITS FOR THOSE WHO USE AND GENERATE NEW KNOWLEDGE?}

TRACK gives those who use knowledge the opportunity to affect how research is interpreted and used. All readers are welcome to post a comment. The Issue in Brief, ${ }^{12}$ which features lay summaries of the research articles, is accessible from the Annals homepage. The Issue in Brief is an attempt to make the Annals and the TRACK discussion accessible to a wide audience. ${ }^{13}$ In recent months, the conversation has been increasingly interactive-with dialogue among readers and between readers and authors.

In addition, TRACK gives authors immediate feedback and an opportunity to engage a wide readership community. When an article is accepted for publication, we request from the authors a list of potential commentators. In addition, the editors review each accepted article to consider the different constituencies that might potentially be affected by the new knowledge in the article. Using both these sources, we invite researchers, content experts, patients, community members, clinicians, policy makers, educators, and others to comment. Along with the excellent work that the Annals publicist, Angela Lower, does in disseminating findings to the lay and professional media, this process gives authors direct feedback on 
their work, as well as the opportunity to interact with the diverse individuals and groups affected by their research and writing.

We are grateful to the many TRACK participants, ${ }^{14}$ and encourage readers and authors to continue to participate in creating an intellectual center for the advancement of health and generalist health care.

To read or post commentaries in response to this article, see it online at http://www.annfammed.org/cgi/content/full/2/6/611.

\section{References}

1. Stange KC, Phillips WR, Acheson LS, et al. Welcome to the Annals of Family Medicine. Ann Fam Med. 2003;1:2-4.

2. Stange KC. On TRACK: the first 20 days. Ann Fam Med. 2003;1:119120

3. Stange KC. On TRACK: questions, interpretation, exhortation. Ann Fam Med. 2004;2:514-517

4. Future of Family Medicine Project Leadership Committee. The future of family medicine: a collaborative project of the family medicine community. Ann Fam Med. 2004;2(Suppl 1):S3-32.
5. Stange KC. The future of family medicine? Reflections from the front lines reveal frustration and opportunity. Ann Fam Med. 2004;2:274-277

6. Oeffinger KC, Mertens AC, Hudson MM, et al. Health care of young adult survivors of childhood cancer: a report from the Childhood Cancer Survivor Study. Ann Fam Med. 2004;2:61-70.

7. McCord G, Gilchrist VJ, Grossman SD, et al. Discussing spirituality with patients: a rational and ethical approach. Ann Fam Med. 2004;2:356-361.

8. Borrell-Carrio F, Epstein RM. Preventing errors in clinical practice: a call for self-awareness. Ann Fam Med. 2004;2:310-316.

9. Woolf SH, Kuzel AJ, Dovey SM, Phillips RL Jr. A string of mistakes: the importance of cascade analysis in describing, counting, and preventing medical errors. Ann Fam Med. 2004;2:317-326.

10. Fiscella K, Franks P. Should years of schooling be used to guide treatment of coronary risk factors? Ann Fam Med. 2004;2:469-473.

11. Mainous AG III, Goodwin MA, Stange KC. Patient-physician shared experiences and value patients place on continuity of care. Ann Fam Med. 2004;2:452-454.

12. Stange KC. In this issue: practice change and patient safety. Ann Fam Med. 2004:2:290-292.

13. Carmichael M. Medicine for the masses. Newsweek. June 10, 2003.

14. Thank you, TRACK participants. Ann Fam Med. 2004;2(3):3 of cover. 